\title{
A Case of Secondary Hemophagocytic Lymphohistiocytosis in an Adult Patient Treated with Concurrent Dexamethasone and Interleukin-1 Receptor Blockade
}

\author{
Vikas Sunder, MD
}

\section{INTRODUCTION}

Hemophagocytic Lymphohistiocytosis $(H L H)$ is a rare life-threatening syndrome of overwhelming inflammation caused by activation and proliferation of T-lymphocytes and hemophagocytic macrophages. ${ }^{1}$ This uncontrolled proliferation of macrophages creates a cytokine storm with resultant tissue damage. HLH is associated with clinical and laboratory findings which include fever, cytopenias, hepatic dysfunction, splenomegaly, and marked hyperferritinemia.1-3 There exists limited epidemiologic data on adult (age $\geq 18$ years) cases of $\mathrm{HLH}$, and its incidence is uncertain. ${ }^{2.4} \mathrm{HLH}$ can be due to inherited mutations causing immune system dysregulation or secondary to underlying malignancy, infection, or rheumatologic condition. Macrophage activation syndrome (MAS) refers to HLH that occurs secondary to rheumatologic diseases. ${ }^{5}$ Approximately $8 \%$ of HLH cases in adults occur secondary to rheumatologic diseases. ${ }^{4}$ The overall 30-day mortality for $\mathrm{HLH}$ in adult patients is approximately $44 \%$ and can be related to the underlying trigger with malignancy-associated HLH patients having a higher mortality. ${ }^{4}$ A key barrier to $\mathrm{HLH}$ treatment in adults is delay in diagnosis given the lack of specific laboratory findings to distinguish it from bacterial sepsis. ${ }^{1,2}$ The treatment for HLH in adults, beyond early initiation of steroids, remains unclear given its rarity, with much of our understanding of HLH derived from the pediatric literature. ${ }^{5}$

\section{CASE PRESENTATION}

A 26-year-old man presented to an outside Emergency Department (ED) with 3 days of fevers to $103^{\circ} \mathrm{F}$, headache, and rash on his upper chest and upper extremities. He was discharged home with ibuprofen, but represented to the ED when his fevers did not resolve. The patient had a history notable for Raynaud's syndrome diagnosed as a toddler. Five months prior to admission, he was hospitalized for a pyogenic hepatic abscess for which he underwent percutaneous drainage and a 6-week course of ciprofloxacin and metronidazole. His only complaint was vague right upper abdominal soreness. Vital signs were notable for heart rate of 115 beats/minute and fever to $102.2^{\circ} \mathrm{F}$.

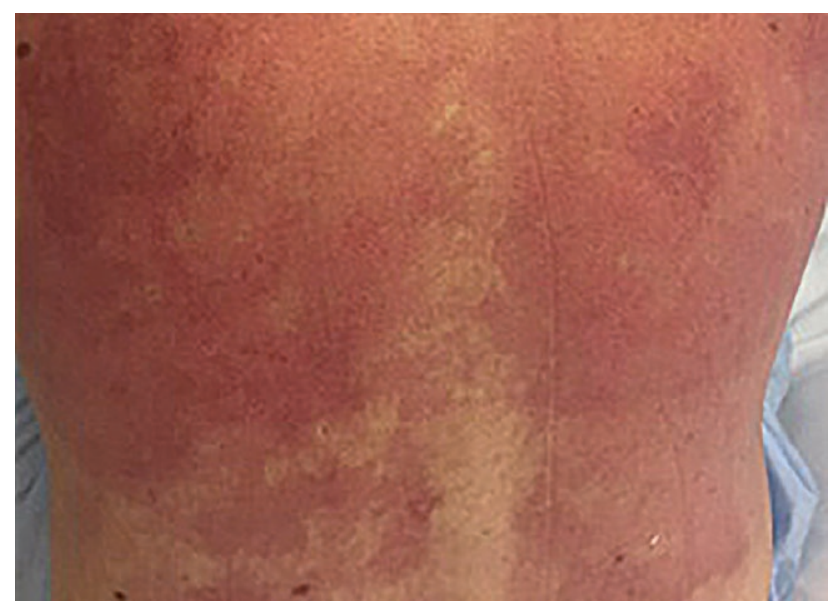

Figure 1. Erythematous rash involving the back.

Physical exam was significant for conjunctival injection and icterus, tachycardia, and blanching erythematous patches involving the chest, upper arms and back (Figure 1). The patient's admission labs were notable for hyperbilirubinemia, transaminitis, thrombocytopenia, and leukopenia with significant bandemia (Table 1)

Table 1: Labs for Admission to the hospital

\begin{tabular}{|l|c|c|c|}
\hline \multicolumn{1}{|c|}{ Lab } & Result & Lab & Result \\
\hline Hemoglobin (g/dL) & $13.2 \mathrm{~L}$ & AST (IU/L) & $480 \mathrm{H}$ \\
\hline WBC (B/L) & $\begin{array}{c}2.8 \text { with } 66 \% \\
\text { bands L }\end{array}$ & ALT (IU/L) & $591 \mathrm{H}$ \\
\hline Platelets (B/L) & $86 \mathrm{~L}$ & $\begin{array}{c}\text { Total Bilirubin } \\
\text { (mg/dL) }\end{array}$ & $3.9 \mathrm{H}$ \\
\hline BUN (mg/dL) & 8 & Albumin (g/dL) & 3.9 \\
\hline Creatinine (mg/dL) & 0.9 & ANA titer & $>1: 640 \mathrm{H}$ \\
\hline Ferritin (ng/mL) & $6881 \mathrm{H}$ & $\begin{array}{c}\text { Anti-RNP/SM } \\
\text { ELISA (U/mL) }\end{array}$ & $>1562 \mathrm{H}$ \\
\hline LDH (IU/L) & $1064 \mathrm{H}$ & CRP (mg/dL) & $12.1 \mathrm{H}$ \\
\hline
\end{tabular}


Table 2: HLH-2004 Criteria for Hemophagocytic Lymphohistiocytosis Observed in Case

\begin{tabular}{|l|l|}
\hline HLH-2004 Diagnostic Criteria & \multicolumn{1}{|c|}{ Patient } \\
\hline Fever $38.5^{\circ} \mathrm{C}$ & *Temperature $39.2^{\circ} \mathrm{C}$ on admission \\
\hline Splenomegaly & $\begin{array}{l}\text { *Present on multiple imaging } \\
\text { modalities abdominal ultrasound, } \\
\text { CT scan of abdomen }\end{array}$ \\
\hline $\begin{array}{l}\text { Cytopenia with } 2 \text { of following: } \\
\text { hemoglobin }<9 \mathrm{~g} / \mathrm{dL}, \\
\text { Platelets }<100 \text { (B/L), absolute } \\
\text { neutrophil count }<1000\end{array}$ & $\begin{array}{l}\text { ANC } 2548 \text { on admission, platelet } \\
\text { count } 81 \text { (B/L) }\end{array}$ \\
\hline $\begin{array}{l}\text { Hypertriglyceridemia } \\
\text { and/or hypofibrinogenemia }\end{array}$ & $\begin{array}{l}\text { Fibrinogen } 257 \text { mg/dL, Triglycerides } \\
144 \text { mg/dL (Within normal limits) }\end{array}$ \\
\hline $\begin{array}{l}\text { Hemophagocytosis in } \\
\text { bone marrow, spleen, } \\
\text { lymph node or liver }\end{array}$ & $\begin{array}{l}* \text { Bone marrow biopsy with increased } \\
\text { number of macrophages with } \\
\text { hemophagocytic activity }\end{array}$ \\
\hline $\begin{array}{l}\text { Low or absent } \\
\text { Natural Killer cell activity }\end{array}$ & $\begin{array}{l}\text { Flow Cytometry with NK cells making } \\
\text { up } 6 \% \text { of lymphocyte lineage }\end{array}$ \\
\hline $\begin{array}{l}\text { Ferritin>500 ng/mL } \\
\text { Elevated soluble CD25 (IL-2) } \\
\text { receptor (U/mL) }\end{array}$ & $* 6881$ ng/mL \\
\hline
\end{tabular}

\section{DIFFERENTIAL DIAGNOSIS}

Sepsis was at the top of the differential so the patient was started on broad spectrum antibiotics with daptomycin, aztreonam, and doxycycline to cover for arthropodborne infection given the high fevers and rash. A computed tomography (CT) scan of the abdomen/pelvis with contrast was performed and showed scarring at the site of the previous hepatic abscess and splenomegaly. The absence of a new hepatic abscess on imaging, along with the patient's upward trending fever curve over the next 2 days while on broad spectrum antibiotics moved the suspected diagnosis towards a non-infectious cause of severe inflammatory disease. The patient's ferritin level dramatically increased from $6,800 \mathrm{ng} / \mathrm{mL}$ on admission to $10,000 \mathrm{ng} / \mathrm{mL}$ on day 3 . The antinuclear antibody (ANA) titer resulted as $>1: 640$, and Anti-RNP/Sm ELISA was $>1562 \mathrm{U} / \mathrm{mL}$, concerning for an underlying autoimmune condition. A soluble serum interleukin-2 (IL-2) receptor level was elevated to $3,300 \mathrm{U} / \mathrm{mL}$. A bone marrow biopsy showed an increased level of macrophages, some of which contained phagocytized cells. Given the composite of this primary data, along with worsening clinical status, $\mathrm{HLH}-2004$ diagnostic criteria was applied and unified this patient's clinical syndrome as HLH based on meeting five of the eight criteria (Table 2).

\section{OUTCOME AND FOLLOW-UP}

Treatment with IV dexamethasone was initiated on day 3 of admission for a suspicion of HLH. Intravenous Immunoglobulin (IVIG) $1 \mathrm{~g} / \mathrm{kg} /$ day for two doses and anakinra $100 \mathrm{mg}$ twice daily were also initiated on day 4 of admission given the lab-work suggesting an underlying rheumatologic trigger. Etoposide, a recommended treatment for non-rheumatologic HLH, was not given due to this patient's extensive hepatic disease, pancytopenia, and likely rheumatologic trigger. ${ }^{6}$ The patient's fever curve, ferritin level, and transaminases down-trended, and his rash greatly improved over the next few days. Dexamethasone was stopped 30 days after discharge based on improving lab-work and the anakinra is to be continued indefinitely with rheumatology follow-up. 60 days after initial admission, the patient's ferritin level normalized, and he returned to his baseline functional independence.

\section{DISCUSSION}

$\mathrm{HLH}$ is a life-threatening disease marked by severe uncontrolled inflammation. HLH in adults remains an elusive diagnosis given its non-specific laboratory findings. Studies have shown that marked hyper-ferritinemia $>50,000 \mu \mathrm{g} / \mathrm{L}$ is not predictive of HLH in adult populations, as opposed to pediatric populations in which it is $90 \%$ sensitive and $98 \%$ specific. ${ }^{7}$ The major obstacle to initiating HLH treatment is a delay in diagnosis as was evident in our case. In our patient, the soluble IL-2 receptor level, which reflects the activation of T-cells, was highly elevated in accordance with cytokine mediated organ dysfunction associated with HLH. ${ }^{2,5}$ There is, however, a time delay in obtaining the IL-2 receptor level, which may take 3- 6 days to result. Overall, our patient's presentation was in line with documented cases of adult HLH in that our patient had a fever (93\% of cases), splenomegaly (50\% of cases), elevated ferritin ( $98 \%$ of cases), and hemophagocytosis seen on bone marrow biopsy ( $97 \%$ of cases). ${ }^{4,8-11}$ Given that diagnosis remains a barrier to HLH treatment, future work should focus on developing adult specific diagnostic criteria. In 2014, a research group based in Paris constructed a diagnostic score called the "HScore" which may be used to estimate an individual's risk for reactive hemophagocytic syndrome according to weighted criteria. This tool is freely available online, but it has limitations including non-specific cutoff values for the criteria and it requires further validation in prospective study. ${ }^{12}$

The principle of HLH management is to suppress the unregulated inflammation. ${ }^{2}$ There is a more specific HLH-2004 treatment protocol which comes from pediatric literature and includes an initial 8-week course of chemo-immunotherapy with etoposide, dexamethasone, and cyclosporine A upfront for patients who are less than 
18 years of age and meet HLH-2004 diagnostic criteria. ${ }^{6}$ Early initiation of dexamethasone, which can cross the blood brain barrier, appears to be of benefit in documented adult cases of HLH and was in this case. ${ }^{2}$ Treatment of the underlying trigger can often lead to control or resolution of the secondary $\mathrm{HLH}$. Our patient had an unclear but likely rheumatologic trigger and was treated with anakinra, an IL-1 receptor antagonist. The exact role of IL-1 in HLH is unknown, but considering the end-product of $\mathrm{HLH}$ is an increased production of cytokines, it would make sense to see IL-1 up-regulation. ${ }^{1}$ Anakinra has been used with positive response in patients with HLH secondary to Systemic Juvenile Idiopathic Arthritis, Adult Still's disease, Systemic Lupus Erythematosus, and even Cytomegalovirus infection. ${ }^{13,8,9,11}$ It is clear that not all adult cases of HLH require initiation of the complete $\mathrm{HLH}-2004$ protocol treatment, which includes chemotherapeutics, as these medications carry harmful side effects. ${ }^{2}$ Use of a biological response modifier along with dexamethasone may achieve treatment of secondary $\mathrm{HLH}$ in an adult patient as exemplified by this case. Further reporting of successful treatment regimens is crucial to developing trigger specific $\mathrm{HLH}$ treatment protocols, given that these patients carry different prognoses based on their underlying cause. ${ }^{4}$

\section{KEY POINTS}

- The prompt diagnosis of secondary HLH in adult patients remains elusive in the absence of adult-specific diagnostic criteria. The presence of multiple HLH-2004 criteria along with the progression of laboratory data can be used to support an HLH diagnosis.

- Not all cases of HLH in adult patients require the initiation of HLH-2004 specific therapy. HLH secondary to a rheumatologic trigger may be managed successfully with dexamethasone and IL-1 receptor blockade. Further investigation of HLH treatment in adult patients is needed.

\section{REFERENCES}

1. Schulert GS, Grom AA. Pathogenesis of macrophage activation syndrome and potential for cytokine-directed therapies. Annual review of medicine. 2015;66:145-59

2. Kleynberg RL, Schiller GJ. Secondary hemophagocytic lymphohistiocytosis in adults: an update on diagnosis and therapy. Clin Adv Hematol Oncol. 2012;10(11):726-32

3. McGhee A. Persistent Fever and Pancytopenia: Lupus Flare vs Macrophage Activation Syndrome. The Medicine Forum. 2015;16(1).

4. Parikh SA, Kapoor P, Letendre L, Kumar S, Wolanskyj AP. Prognostic factors and outcomes of adults with hemophagocytic lymphohistiocytosis. Mayo Clin Proc. 2014;89(4):484-92

5. Hayden A, Park S, Giustini D, Lee AY, Chen LY. Hemophagocytic syndromes (HPSs) including hemophagocytic lymphohistiocytosis (HLH) in adults: A systematic scoping review. Blood reviews. 2016;30(6):411-20

6. Henter JI, Horne A, Aricó M, et al. HLH-2004: diagnostic and therapeutic guidelines for hemophagocytic lymphohistiocytosis. Pediatric blood \& cancer 2007:48(2):124-31

7. Schram AM, Campigotto F, Mullally A, Fogerty A, Massarotti E, Neuberg D, Berliner N. Marked hyperferritinemia does not predict for HLH in the adult population. Blood. 2015;125(10):1548-52

8. Durand M, Troyanov Y, Laflamme P, Gregoire G. Macrophage activation syndrome treated with anakinra. The Journal of Rheumatology. 2010:37(4):879-80

9. Kelly A, Ramanan AV. A case of macrophage activation syndrome successfully treated with anakinra. Nature Clinical Practice Rheumatology. 2008:4(11):615-20

10. Reddy S, Rangappa P, Kasaragod A, Kumar AS, Rao K. Haemophagocytic lymphohistiocytosis $(H L H)$ : case series in tertiary referral hospital over three years. J Asso c Physicians India. 2013;61:850-852

11. Divithotawela C, Garrett P, Westall G, Bhaskar B, Tol M, Chambers DC. Successful treatment of cytomegalovirus associated hemophagocytic lymphohistiocytosis with the interleukin 1 inhibitor-anakinra. Respirology case reports. 2016:4(1):4-6.

12. Fardet L, Galicier L, Lambotte O, et al. Development and validation of the HScore, a score for the diagnosis of reactive hemophagocytic syndrome. Arthritis \& Rheumatology. 2014;66(9):2613-20. 